\title{
Green Synthesis and Characterization of Silver Nanoparticles from Stem Bark Extract of Cordia dichotoma G. Forst and Evaluation of their Antioxidant and Antibacterial activities
}

\author{
Gone Swapna, Bhattiprolu Kesava Rao*
}

\section{Gone Swapna, Bhattiprolu Kesava Rao*}

\section{Department of Chemistry,}

Acharya Nagarjuna University, Guntur, Andhra Pradesh, INDIA.

Correspondence

Prof. Bhattiprolu Kesava Rao

Department of Chemistry, Acharya Nagarjuna University College of sciences Acharya Nagarjuna University, Guntur-522510, Andhra Pradesh, INDIA.

Phone no: +919030824542

Email id: krbhattiprolu@gmail.com

History

- Submission Date: 19-11-2020;

- Review completed: 02-02-2021;

- Accepted Date: 10-05-2021

DOI : $10.5530 /$ pres. 13.3 .8

Article Available online

http://www.phcogres.com

\section{Copyright}

(C) 2021 Phcog.Net. This is an openaccess article distributed under the terms of the Creative Commons Attribution 4.0 International license.

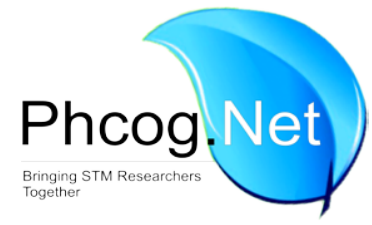

\begin{abstract}
Background: There is a lack of scientific evidence for the fabrication of silver nanoparticles (AgNPs) using stem bark extract of medicinal plant Cordia dichotoma and its potential therapeutic applications. Objectives: In our present study we contemplated using Cordia dichotoma extract for fabricating AgNPs and to analyze their potential applications as antioxidant and biocidal agents. Materials and Methods: AgNPs were fabricated by bio reduction of silver nitrate solution with bark extract of Cordia dichotoma. The fabricated AgNPs were characterized using U.V visible, FT-IR, XRD, SEM, EDAX, particle size analyzer, and zeta potential. Further, evaluated for their potential antioxidant activity and compared with the crude extract of Cordia dichotoma and with standard ascorbic acid. The antibacterial activity was performed against both Gram-positive and Gram-negative bacteria. Results: The AgNPs were synthesized and UV spectra showed maximum absorbance at $430 \mathrm{~nm}$, which is the characteristic feature of AgNPs. The XRD peaks at (111), (220), and (311) indicate the existence of silver with a crystalline structure. The FT-IR spectra in the range of 1516 to $1634 \mathrm{~cm}^{-1}$ reflected the presence of phenol groups which acted as the capping agents for synthesized AgNPs. The SEM images confirmed the spherical structure of AgNPs that formed aggregates with phytochemicals and appeared as composites. The average size of AgNPs is $39.8 \mathrm{~nm}$ and exhibited good stability as evident from the zeta potential value of -33. Conclusion: Phytomediated eco-friendly synthesized and structurally characterized AgNPs can act as antioxidants and exhibited antibacterial activity against Gram-positive (Staphylococcus aureus) and Gram-negative (Escherichia coli) pathogenic bacteria.
\end{abstract}

Key words: Cordia dichotoma, Silver nanoparticles, Antioxidants, Antibacterials.

\section{INTRODUCTION}

Globally much research was focused on the usage of different organic and inorganic metals, and their alloys for the synthesis of metal nanoparticles. ${ }^{[1]}$ Various elements and metals such as $\mathrm{CeO}_{2}, \mathrm{FeO}, \mathrm{SiO}_{2}, \mathrm{TiO}_{2}$, and $\mathrm{ZnO}$ are often used apart from other metal elements like $\mathrm{Ag}, \mathrm{Au}, \mathrm{Fe}, \mathrm{Cu}, \mathrm{Pt}, \mathrm{Pd}, \mathrm{Ni}$, and $\mathrm{Co}$, etc for the synthesis of nanoparticles. ${ }^{[2]}$ These metal-based nanostructures have a small size and high surface area. Among all these metals and materials silver (Ag) occupies the predominant position. Silver and its usage for therapeutic applications are as old as human civilization. The fabrication of silver nanoparticles using plant extracts rich in secondary metabolites is the recently recognized and developed study for further enhancing the applications of silver. In this process, silver is reduced to silver nanoparticles and plant extracts act as a capping and reducing agent of silver nitrate into silver nanoparticles. ${ }^{[3]}$ The ultra-small size, biocompatibility and nontoxic nature of normal

tissues and eukaryotic cells at the nanoscale level are major advantages of nanoparticle applications, especially as therapeutic agents. ${ }^{[4]}$

The Boraginaceae family is one of the richest plant families in terms of medicinal plants with huge therapeutic and cosmetic applications. It Comprises plants that have important therapeutic and cosmetic applications. $^{[5]}$ The pharmacological effect and efficiency is associated with the presence of diverse phytochemicals such as alkaloids, flavonoids, naphthoquinones, phenols, terpenoids, and many more secondary metabolites. Cordia dichotoma belongs to the Boraginaceae family and native to India and other Asian countries. Cordia dichotoma is well known for its therapeutic and medicinal applications like curing diseases especially diarrhea, dyspepsia, dysentery fever, headache, and stomach ache, etc. ${ }^{[6]}$

Cite this article: Swapna G, Rao BK. Green Synthesis and Characterization of Silver Nanoparticles from Stem Bark Extract of Cordia dichotoma G. Forst and Evaluation of their Antioxidant and Antibacterial activities. Pharmacog Res. 2021;13(3):158-64. 


\section{MATERIALS AND METHODS}

\section{Plant extract preparation}

The Cordia dichotoma stem bark was collected, authenticated by the taxonomist, dried and powdered. The powder was sieved with mesh no 22 and stored until further use. From the plant stem bark powder $3 \mathrm{~g}$ was taken, boiled with $100 \mathrm{~mL}$ of double distilled water to extract the Phytochemicals and secondary metabolites. The extract was filtered with Whatmann No- 1 filter paper and diluted with $300 \mathrm{~mL}$ of double distilled water. Obtained solution was used for the synthesis of AgNPs. ${ }^{[7]}$

\section{Synthesis of AgNPs}

The AgNPs were synthesized with the modified protocol of ParlinskaWojtan. ${ }^{[8]}$ For this purpose, $1 \mathrm{mM}$ silver nitrate solution and Cordia dichotoma plant stem bark aqueous extract were mixed in different ratios and finally, (1:10) ratio of plant extract to $1 \mathrm{mM} \mathrm{AgNO}_{3}$ was standardized. $400 \mathrm{ml}$ of plant extract $(7.5 \mathrm{mg} / \mathrm{mL})$ was added to $4 \mathrm{~L}$ of $1 \mathrm{mM}$ silver nitrate solution at room temperature and stored in a dark room for $24 \mathrm{hr}$. Further, the reaction mixture was subjected to centrifugation at 10,000 RPM at $4^{\circ} \mathrm{C}$. The supernatant was discarded and the AgNPs were deposited as pellets at the bottom of the centrifuge tube. The obtained pellets were air-dried at $25^{\circ} \mathrm{C}$ for three days to make them fine powder.

\section{Characterization of fabricated AgNPs-Cordia dichotoma composite}

The fabricated, fine powdered AgNPs- Cordia dichotoma composite was subjected to further physical and chemical characterization using various spectroscopic and microscopic techniques as follows.

\section{UV-Visible spectroscopy}

The reduction of silver ions was observed by the periodical analysis of the $5 \mathrm{ml}$ of the AgNPs reaction mass sample by the U.V (Ultra Violet) spectrum (Model: Thermo scientific) in the range of $200-800 \mathrm{~nm}$ to detect the surface Plasmon resonance peak of AgNPs. The spectra were recorded at different time intervals of every $4 \mathrm{hr}$ during the reaction incubation time. ${ }^{[9]}$

\section{Fourier Transform Infra Red (FT-IR) spectroscopy}

The fabricated AgNPs were subjected to FT-IR spectral analysis using BRUKER spectrometer to identify the functional groups associated with the bio reduction and capping agents present on the synthesized composite. ${ }^{[10]}$

\section{XRD analysis}

The diffraction pattern of fabricated nanoparticles was measured on the X-ray diffractometer. (PW 1830, Philips) for identification of silver element. ${ }^{[11]}$

\section{SEM with EDAX}

The Scanning Electron Microscopy (SEM) analysis was carried out on the Field emission scanning electron microscope (FESEM) Carl Zeiss model Merlin compact microscope using a $30 \mathrm{Kev}$ electron beam. The AgNPs sample was coated on the carbon (silica) coated film or copper grid. The film was allowed to dry after coating it with AgNps under a mercury lamp for $5 \mathrm{~min}$ and then SEM images were captured at different magnifications.

Energy-dispersive X-ray Spectroscopy (EDAX) was recorded by using an Oxford instrument X-Max ${ }^{\mathrm{N} D D}\left(50 \mathrm{~mm}^{2}\right)$ system and Integrated Calibration and Application tool (INCA) analysis software which is coupled with the SEM instrument. The SEM coupled with EDAX was used to identify the morphology and elemental composition of the fabricated AgNPs. ${ }^{[12]}$

\section{Zeta potential}

The stability of fabricated AgNPs was measured by analyzing the zeta potential. ${ }^{[13]}$

\section{Particle size analysis}

The size of the fabricated AgNPs was measured on Horiba scientific SZ- 100 instrument. ${ }^{[14]}$

\section{Biological activities of AgNPs}

The fabricated AgNPs were investigated for potential antioxidant and antibacterial activities.

\section{Antioxidant activity}

Antioxidant assay for the synthesized AgNPs was evaluated based on the DPPH assay method. The modified method Brand-Williams was used for the analysis. ${ }^{[15]}$ The antioxidant activity was measured for Cordia dichotoma plant extract, fabricated AgNPs and compared with the standard ascorbic acid. For this purpose, $5 \mathrm{mg}$ of plant extract and AgNPs are dissolved in $1 \mathrm{~mL}$ of HPLC water respectively and from this stock solution, aliquots of plant extract and AgNPs are prepared in 25, 50, 100, $150,200 \mu \mathrm{g} / \mathrm{mL}$ concentrations. $3 \mathrm{~mL}$ of the extract solution was added to the $1 \mathrm{~mL}$ of $0.1 \mathrm{mM}$ solution of DPPH in methanol. The absorbance was calibrated after $30 \mathrm{~min}$ at $517 \mathrm{~nm}$. DPPH in methanol was used as a negative control. The percentage of scavenging activity was measured by the following equation. ${ }^{[16]}$

$$
\text { DPPH Scavenged } \left.(\%)=\left[\left(\mathrm{A}_{\text {control }}-\mathrm{A}_{\text {test }}\right) / \mathrm{A}_{\text {control }}\right)\right] \times 100 \text {. }
$$

\section{Antibacterial activity of AgNPs}

The synthesized AgNPs were assessed for their antibacterial activity by using the disc diffusion method. The antibacterial activity was evaluated against two Gram-positive bacteria Staphylococcus aureus, and Lactobacillus bacteria. The Gram-negative bacteria used for evaluation include Escherichia coli and Enterobacter. Streptomycin was used as the standard for comparison. $50 \mu \mathrm{L}$ of $24 \mathrm{hr}$ old bacterial cultures were spread over the surface of nutrient agar plate using an aseptic swab. Sterile antimicrobial susceptibility discs were used and they were loaded with 20,30, 40and $50 \mu \mathrm{L}$ of fabricated AgNPs solution of $1 \mathrm{mM}$ concentration. The AgNPs solution-loaded discs were placed on the agar plate and incubated at $37^{\circ} \mathrm{C}$ for $24 \mathrm{hr}$. After the incubation period, the antibacterial activity of AgNPs was assessed by measuring the zone of inhibition using a calibrated scale. ${ }^{[17]}$

\section{RESULTS}

\section{UV-Visible spectroscopy}

The nanoparticles were fabricated by reducing silver nitrate into AgNPs by using Cordia dichotoma stem bark aqueous extract as a bio reductant and capping agent. The synthesis was initially confirmed by observing colour change from light yellow to red color and further confirmed by UV-Visible spectroscopy. A characteristic broad peak at $430 \mathrm{~nm}$ was observed. The result of UV-Visible spectroscopy was represented in Figure 1. The UV analysis was performed to identify the Surface Plasmon Resonance characteristic feature of fabricated AgNPs. An increase in the absorbance was observed with an increase in time and evaluated up to $24 \mathrm{hr}$. There was no significant increase in the absorbance observed after $20 \mathrm{hr}^{[18]}$

FT-IR

The FT-IR spectrum demonstrated the presence of $1516,1634 \mathrm{~cm}^{-1}$ $1650,2347,2825$, and 3200 to $3900 \mathrm{~cm}^{-1}$ peaks. These peaks are 


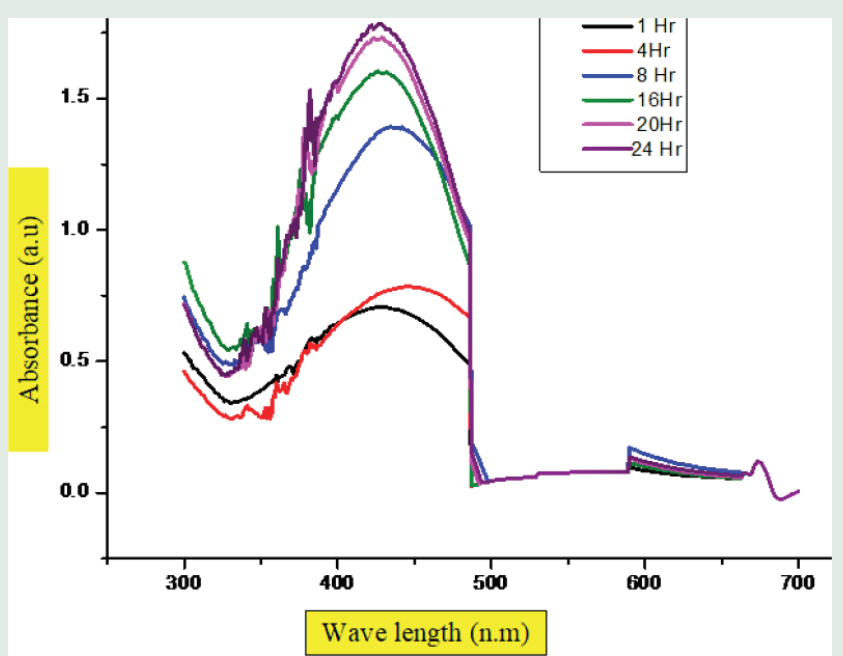

Figure 1: U.V visible spectrum of AgNPs at different time intervals.

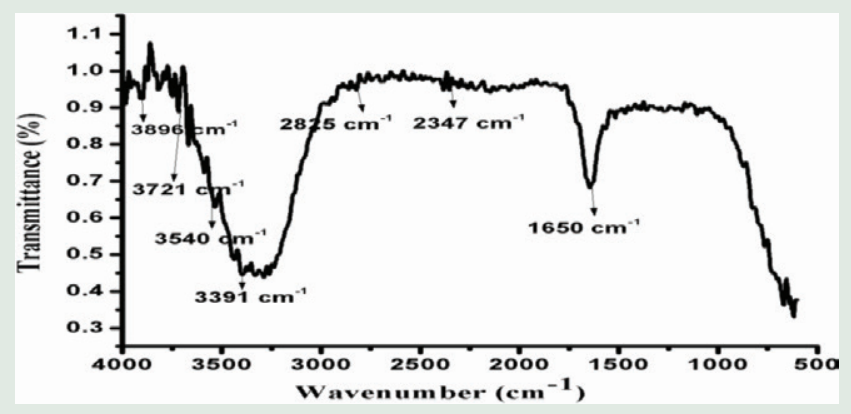

Figure 2: FT-IR spectra of the synthesized AgNPs.

characteristic features of functional groups having phenolic compounds and flavonoids. For instance, the strong intense peaks at 1650represent the $(\mathrm{C}=\mathrm{C})$ groups from aromatic rings. 2347 represents $(\mathrm{C} \equiv \mathrm{O})$, aldehydic $\mathrm{C}-\mathrm{H}$ stretch at $2825 \mathrm{~cm}$, the peaks in the range of 3200 to 3900 were due to the $\mathrm{OH}$ stretching in alcohols and phenols. ${ }^{[19]}$ The FT-IR spectrum is represented in Figure 2.

\section{XRD analysis}

The XRD pattern was measured and analyzed from a diffraction angle range of $0^{\circ}$ to $80^{\circ}$. The XRD spectrum was represented in Figure 3 . The XRD diffraction peaks can be indexed to the (111), (200), (220) and (3 11 ) reflections of face-centred cubic structure of metallic silver which appropriately matched the standard diffraction data of silver reported by the joint committee on powder diffraction standards (JCPDS) file no: 04-0783. The smaller size of AgNPs in the sample resulted in the line widening of peaks. The other peaks at $2 \theta=27.19^{\circ}, 32.24^{\circ}, 54.69^{\circ}, 57.36^{\circ}$, and $76.58^{\circ}$ have resulted from the secondary metabolites of AgNPs. ${ }^{[20]}$

\section{SEM analysis}

The SEM images of AgNPs-Cordia dichotoma composite revealed that they are in spherical shape and agglomerated. SEM micrographs for synthesized silver nanoparticles were recorded at $100 \mu \mathrm{M}$ and $200 \mu \mathrm{M}$, It was evident from SEM analysis is that the AgNPs are spherical closely arranged and agglomerated. ${ }^{[21]}$ The secondary metabolites acted as

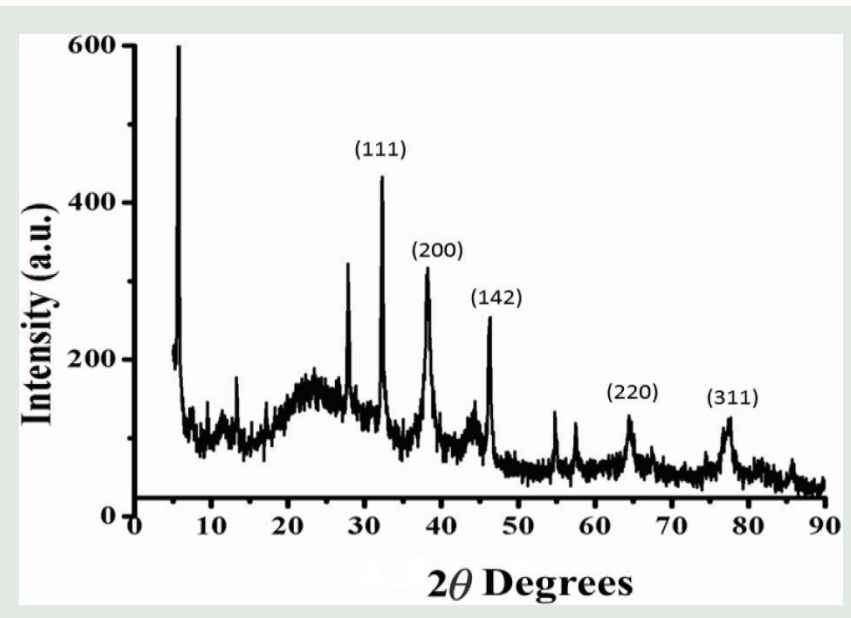

Figure 3: XRD of the synthesized AgNPs.

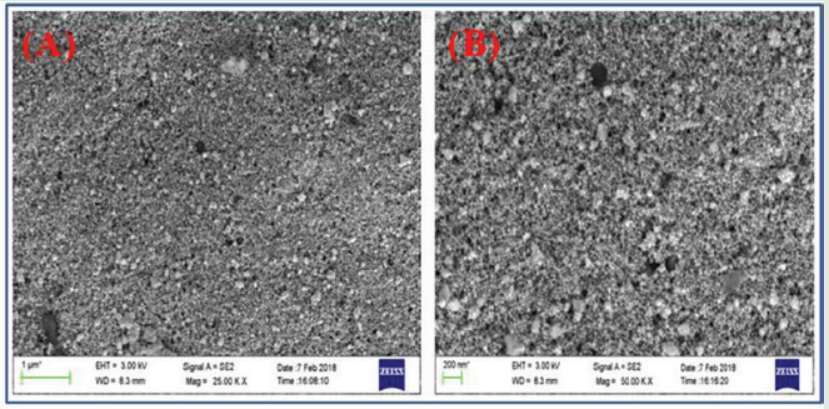

Figure 4: Corresponds to the SEM images of the synthesized AgNPS. Image (A) corresponds to the AGNPS-Plant extract composite at lower magnification. Image (B) corresponds to the SEM image at further higher magnification.

reducing and capping agents. The SEM images at low and high magnification were represented in Figure 4.

\section{EDAX}

The EDAX spectrum revealed the presence of elemental silver with a percentage of $80 \%$. Apart from silver, the EDAX spectrum also revealed the presence of other elements like carbon, oxygen, sodium, and nitrogen at different concentrations which are from the phytoconstituents. The EDAX spectrum was represented in Figure 5.

\section{Zeta potential}

Zeta potential technique measures the long-term stability of colloidal AgNPs. The metal nanoparticles with a large positive or negative zeta potential, repel each other and do not agglomerate. Agglomeration occurs in nanoparticles that have less positive and less negative charges because of the absence of repulsive forces. From the zeta potential analysis, the fabricated AgNPs exhibited a value of -33 , which indicated the good stability of AgNPs. The zeta potential spectrum was represented in Figure 6.

\section{Particle size analysis}

The particle size of the fabricated AgNPs showed an average particle size of $39.8 \mathrm{~nm}$. The AgNPs exhibited relatively narrow particle size 

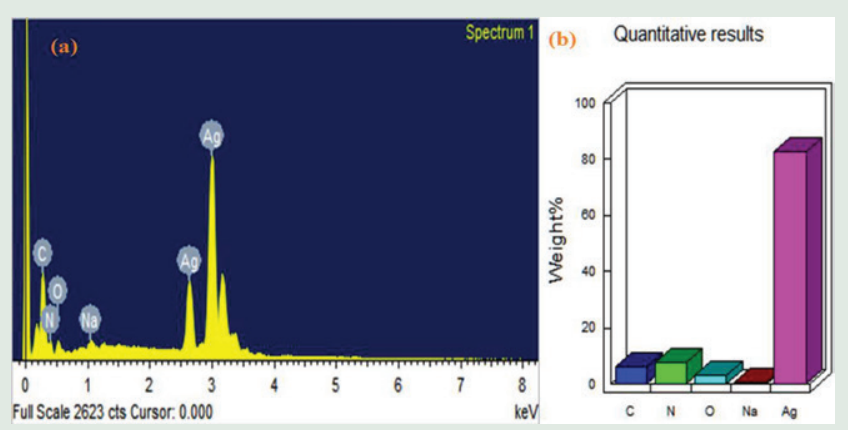

Figure 5: EDAX spectrum of the synthesized AgNPs. Image (a) corresponds to the EDAX spectrum with different elements. Image (b) corresponds to the bar graph representation of various elements as represented in weight\%.

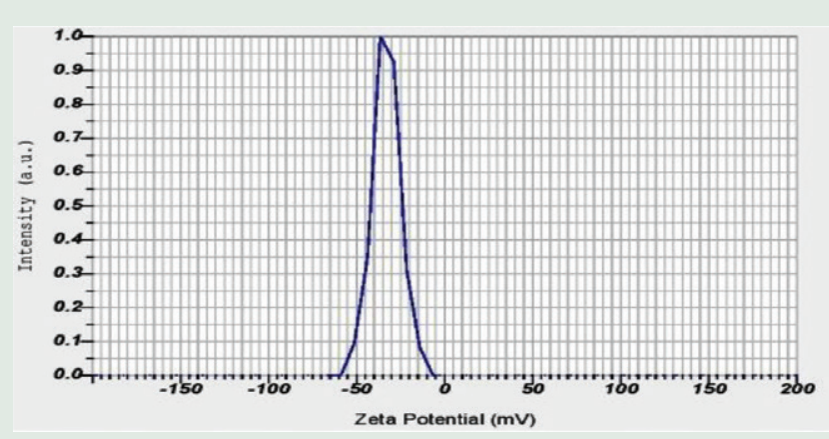

Figure 6: Zeta Potential of the synthesized AgNPs.

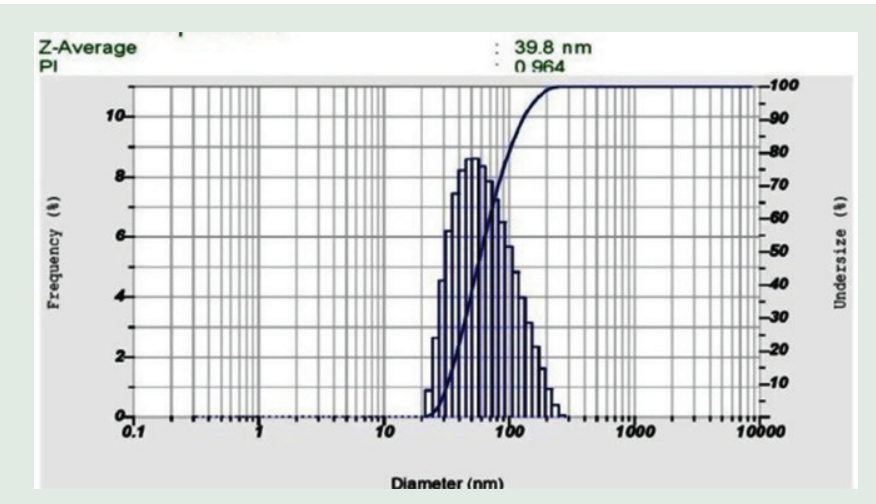

Figure 7: Particle size analysis spectra of the synthesized AgNPs.

distribution $(\mathrm{z}$-average $=39.9 \mathrm{~nm})$. Nanoparticle size distribution is related to the PDI value. PDI is measured as 0.964 . The results of particle size analysis were represented in Figure 7. The PDI value of 0.96 is considered as highly polydisperse system. The most prominent, efficient, and effective nanoparticles were determined to be in the range of 1-100 nm size. Such a novel size gives these particles the characteristics of both bulk materials and molecular structures. The smaller the size, the increase in surface area with altered and enhanced physical and chemical properties while compared to their counterparts which are at a large size.

\section{Antioxidant activity}

The antioxidant activity of fabricated AgNps and Cordia dichotoma stem bark aqueous extract, along with the standard ascorbic acid was represented in Table 1 and Figure 8 . From these results, we can confer that the percentage of DPPH scavenged activity of AgNPs is greater than Cordia dichotoma stem bark aqueous extract alone, and the activity is close to the standard ascorbic acid. The present study of antioxidant activity for Cordia dichotoma plant stem bark mediated silver nanoparticles is the first-ever report.

The $\mathrm{IC}_{50}$ values of the C. dichotoma, AgNPs of C. dichotoma and ascorbic acid are $96.30,78.9$ and $70.1 \mu \mathrm{g} / \mathrm{mL}$ respectively, and the value of AgNPs are less than the plant extract itself and close to the standard ascorbic acid. The $\mathrm{IC}_{50}$ values were calculated by linear regression analysis of dose response curve plotting between $\%$ of absorbance and different concentration of extracts. ${ }^{[22]}$

\section{Antibacterial activity}

The antibacterial activity was measured using the disc diffusion method. After $24 \mathrm{hr}$ of incubation, the zone of inhibition in $\mathrm{mm}$ was measured. The antibacterial activity results images were represented in Figure 9 along with the images of standard streptomycin. The activity of AgNPs against Staphylococcus aureus was high $(16.1 \pm 0.21)$ at $50 \mu \mathrm{L}$ concentrations when compared to other strains. The results as represented from Table 2 suggested that AgNPs showed an almost similar effect on both Gram-positive and Gram-negative bacteria conferring that silver nanoparticles can act as broad-spectrum antibiotics.

Table 1: DPPH scavenged percentage of Cordia dichotoma bark, Cordia dichotoma AgNPs and standard Ascorbic acid.

\begin{tabular}{cccc}
\hline $\begin{array}{c}\text { Concentrations } \\
(\mu \mathrm{g} / \mathrm{mL})\end{array}$ & $\begin{array}{c}\text { Cordia dichotoma } \\
\text { Aqueous stem } \\
\text { bark extract DPPH } \\
\text { scavenged }(\%)\end{array}$ & $\begin{array}{c}\text { Cordia dichotoma } \\
\text { AgNPs DPPH } \\
\text { scavenged }(\%)\end{array}$ & $\begin{array}{c}\text { Ascorbic } \\
\text { acid DPPH } \\
\text { scavenged } \\
(\%)\end{array}$ \\
\hline 25 & $27.8 \pm 0.43$ & $30.4 \pm 0.08$ & $32.5 \pm 0.16$ \\
50 & $44.2 \pm 0.53$ & $46.4 \pm 0.12$ & $48.24 \pm 0.11$ \\
100 & $55.9 \pm 0.16$ & $58.6 \pm 0.24$ & $60.2 . \pm 0.12$ \\
150 & $62.2 \pm 0.20$ & $68.5 \pm 0.08$ & $72.8 \pm 0.16$ \\
200 & $74.5 \pm 0.16$ & $81.4 \pm 0.16$ & $88.7 \pm 0.12$ \\
\hline
\end{tabular}

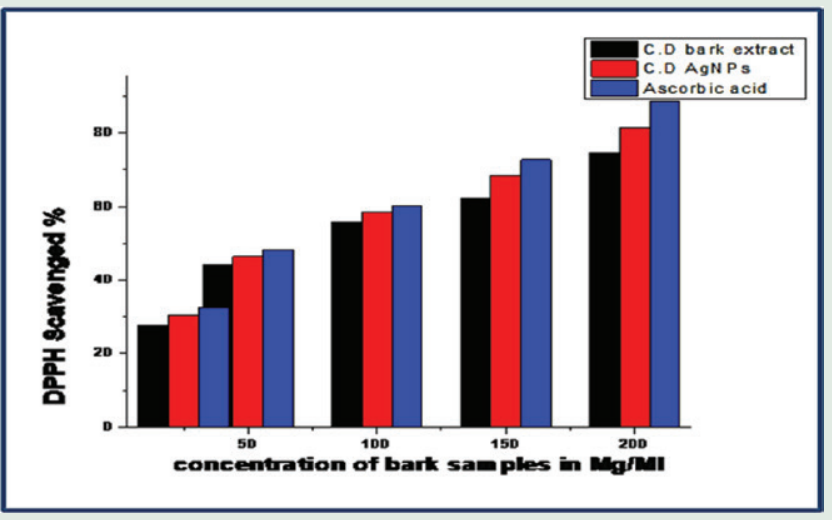

Figure 8: Corroborates the graphical representation of the antioxidant activity of the synthesized AgNPs. 


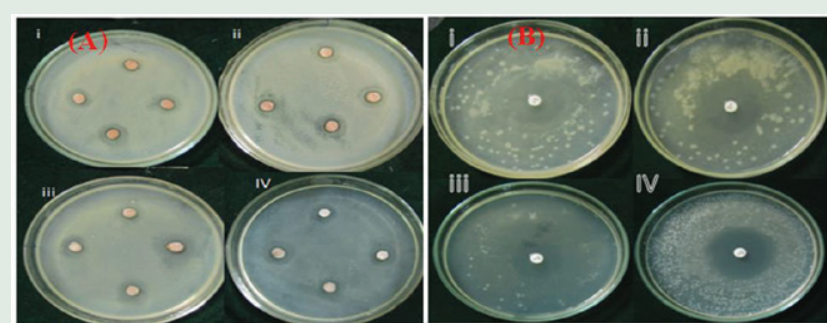

Figure 9: Image section A corresponds to the antibacterial activity of AgNPs. i. Escherichia coli, ii. Enterobacter sp, iii. Staphylococcus aureus, iv. Lactobacillus. Images from B correspond to the antibacterial activity against standard streptomycin. Imag- i. E. coli, ii. Enterobacter, iii. Staphylococcus aureus, iv. Lactobacillus.

Table 2: Zone of inhibition values ( $\mathrm{mm}$ ) of AgNPs at variable concentrations.

\begin{tabular}{|c|c|c|c|c|}
\hline \multirow[b]{2}{*}{$\begin{array}{l}\text { Concentration of } \\
\text { AgNPs ( } \mu \mathrm{L} / \text { disc })\end{array}$} & \multicolumn{4}{|c|}{ Zone of Inhibition of test Organisms (m.m) } \\
\hline & 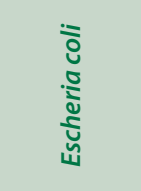 & 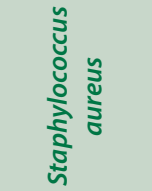 & 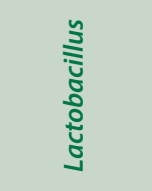 & 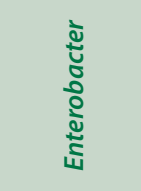 \\
\hline 20 & $11.93 \pm 0.41$ & $12.93 \pm 0.12$ & $13.86 \pm 0.49$ & $12.96 \pm 0.16$ \\
\hline 30 & $12.96 \pm 0.16$ & $13.25 \pm 0.12$ & $14.13 \pm 0.20$ & $13.06 \pm 0.12$ \\
\hline 40 & $13.93 \pm 0.41$ & $14.2 \pm 0.21$ & $15.06 \pm 0.20$ & $14.06 \pm 0.20$ \\
\hline 50 & $15.93 \pm 0.12$ & $16.1 \pm 0.21$ & $16.06 \pm 0.16$ & $15.96 \pm 0.20$ \\
\hline streptomycin & $24.5 \pm 0.40$ & $21.93 \pm 0.33$ & $22.06 \pm 0.20$ & $26.83 \pm 0.28$ \\
\hline
\end{tabular}

\section{DISCUSSION}

Globally, much attention was focused on green synthesized metal nanoparticles because of their ease, one-pot, eco-friendly, and economically feasible methodologies of synthesis and characterization. Based on the current research and available experimental data from the literature, the medicinal plant Cordia dichotoma is the richest source of secondary metabolites with potential therapeutic applications. Phytochemicals exhibit greater reduction and stabilization of metallic chemicals like silver nitrate which can be reduced to silver nanoparticles. Gomathi S et al., 2017 used Eugenia jambolana leaf extract for the fabrication of AgNPs in the presence of plant secondary metabolites like alkaloids, flavonoids, saponins, and sugar compounds. ${ }^{[23]}$ The phenols present in the Cordia dichotoma reduced the silver nitrate to the AgNPs. The methodology followed in this study is a rapid, economically feasible, and most efficient approach for the bio reduction and aggregating AgNPs with therapeutic applications. Many of the researchers used a similar bio reduction method for the synthesis of metallic nanoparticles using plant extracts. The change in color of the reaction mixture was observed after 30 min due to the formation of silver nanoparticles. The broad peak observed in U.V Visible spectroscopy in the range of $410 \mathrm{~nm}$ to $490 \mathrm{~nm}$ is the characteristic feature of silver nanoparticles. The broad peak in U.V Visible spectroscopy is due to Surface Plasmon Resonance. Brause et al., represented that optical absorption spectra of metallic nanoparticles are extensively dominated by Surface Plasmon Resonance and the obtained peak can be correlated with the particle size. With the increase in particle size, the absorbance peak of AgNPs in aqueous medium shifts to longer wavelengths. ${ }^{[24]}$ According to Nikita Dalal et al., The relation between size and wavelength is linear. ${ }^{[25]}$ The FT-IR spectra exhibited the presence of diverse functional groups suggesting and confirming the formation of aggregates and composites of synthesized AgNPs with plant secondary metabolites especially phenols. Reddy NJ synthesized silver nanoparticles using the aqueous extract of Piper longum fruit extract and reported that the polyphenols present as secondary metabolites stabilized the silver nanoparticles. ${ }^{[26]}$ The XRD analysis revealed that they are crystalline in nature with face centered cubic structure (FCC). A similar result of crystalline nature was reported by Moldovan et al. They synthesized spherical AgNPs from Sambucus nigra fruit extract. ${ }^{[27]}$ SEM analysis revealed that they are spherical and compactly arranged. Plant extract directs the size and shape of silver nanoparticles, Logaranjan et al., 2016, prepared the AgNPs using aloe vera, and observed that that aloe vera gel played a prominent role in controlling the size and shape of the AgNPs, ${ }^{[28]}$ by using the plant extract of Fraxinus excelsior, Praveen $\mathrm{M}$ et al., synthesized similar type of spherical shaped silver nanoparticles. ${ }^{[2]}$ The synthesised silver nanoparticles of C.dichotoma also have effective antibacterial activity against Gram-positive bacteria like Staphylococcus aureus, lactobacillus, and against the Gram-negative bacteria Escherichia coli and Enterobacter strains. The variation in the antibacterial activity of silver nanoparticles is due to the variation in the degree of susceptibility for the cell walls of the tested organisms due to their structural variations. The possible mechanism for the antibacterial activity of AgNPs is by binding to the bacterial cell membrane and penetrates the cell, causes cell death. The other mode of action by AgNPs includes synergistic action of silver and AgNPs binds to the sulfur-containing proteins of the cell wall to increase the cell wall permeability of antibiotics.

The AgNPs also exhibits excellent antioxidant properties when compared with the plant extract and the $\mathrm{IC}_{50}$ values are close to the standard ascorbic acid. The lower $\mathrm{IC}_{50}$ values of AgNPs when compared to the plant extract itself are evident that they are effective free radical scavengers. According to jun et al., the $\mathrm{IC}_{50}$ values in the range of $50-100 \mu \mathrm{g} / \mathrm{mL}$ is considered as active free radical activity. ${ }^{[30]}$ The hydroxyl group-containing molecules are responsible for the antioxidant activity. The apigenin, hydroxyl group containing molecule was already reported from the plant. Antioxidant activity of the green synthesized AgNPs were reported in Chenopodium Murale leaf extract ${ }^{[31]}$ Priya et al., 2016 has studied the antioxidant activity of silver and gold nanoparticles from the bark of Plumbago zeylanica and concluded that the AgNPs showed better antioxidant activity than the plant extract itself. ${ }^{[32]}$

Based on our literature survey, we can conclude that the study of antibacterial and antioxidant activity of AgNPs fabricated using the aqueous extract of stem bark of Cordia dichotoma is reported for the first time.

\section{ACKNOWLEDGEMENT}

We are acknowledging the UGC for giving meritorious BSR fellowship (BININ00355344U) and the Department of Bio-Technology, ANU for providing U.V spectral analysis.

\section{CONFLICT OF INTEREST}

The authors declare that there is no conflict of interest.

\section{ABBREVIATIONS}

U.V: Ultra violet spectroscopy; SPR: Surface Plasmon resonance; FT-IR: Fourier Transform Infra-Red spectroscopy; XRD: X-ray powder diffraction; SEM: Scanning Electron Microscopy; EDAX: Energydispersive X-ray Spectroscopy; PDI: Poly dispersity Index; ZOI: Zone of inhibition; DPPH: 2,2-diphenyl-1-picrylhydrazyl, IC $_{50}$ : Half Maximal Inhibitory Concentration. 


\section{REFERENCES}

1. Liu L, Corma A. Metal catalysts for heterogeneous catalysis: From single atoms to nanoclusters and nanoparticles. Chem Rev. 2018;118(10):4981-5079.

2. Foko LP, Meva FE, Moukoko CE, Ntoumba AA, Njila MI, Kedi PB, et al. A systematic review on anti-malarial drug discovery and antiplasmodial potential of green synthesis mediated metal nanoparticles: overview, challenges and future perspectives. Malar J. 2019;18(1):1-4.

3. Khan SU, Anjum SI, Ansari MJ, Khan MH, Kamal S, Rahman K, et al. Antimicrobial potentials of medicinal plant's extract and their derived silver nanoparticles: A focus on honey bee pathogen. Saudi J Biol Sci. 2019;26(7):1815-34.

4. Yetisgin AA, Cetinel S, Zuvin M, Kosar A, Kutlu O. Therapeutic nanoparticles and their targeted delivery applications. Molecules. 2020;25(9):2193.

5. Dresler S, Szymczak G, Wójcik M. Comparison of some secondary metabolite content in the seventeen species of the Boraginaceae family. Pharm Biol. 2017:55(1):691-5.

6. Jamkhande PG, Barde SR, Patwekar SL, Tidke PS. Plant profile, phytochemistry and pharmacology of Cordia dichotoma (Indian cherry): A review. Asian Pac $J$ Trop Biomed. 2013;3(12):1009-12.

7. Zhang XF, Liu ZG, Shen W, Gurunathan S. Silver nanoparticles: Synthesis, characterization, properties, applications, and therapeutic approaches. Int J Mol Sci. 2016;17(9):1534

8. Parlinska-Wojtan M, Kus-Liskiewicz M, Depciuch J, Sadik O. Green synthesis and antibacterial effects of aqueous colloidal solutions of silver nanoparticles using camomile terpenoids as a combined reducing and capping agent. Bioprocess Biosyst Eng. 2016;39(8):1213-23.

9. Singh J, Dutta T, Kim KH, Rawat M, Samddar P, Kumar P. 'Green'synthesis of metals and their oxide nanoparticles: Applications for environmental remediation. J Nanobiotechnology. 2018;16(1):1-24.

10. Arunachalam KD, Annamalai SK. Chrysopogon zizanioides aqueous extract mediated synthesis, characterization of crystalline silver and gold nanoparticles for biomedical applications. Int J Nanomedicine. 2013;8:2375-84.

11. Islam NU, Amin R, Shahid M, Amin M, Zaib S, Iqbal J. A multi-target therapeutic potential of Prunus domestica gum stabilized nanoparticles exhibited prospective anticancer, antibacterial, urease-inhibition, anti-inflammatory and analgesic properties. BMC Compl Alternative Med. 2017;17(1):276.

12. Farooq U, AhmadT, Khan A, Sarwar R, Shafiq J, Raza Y, et al. Rifampicin conjugated silver nanoparticles: a new arena for development of antibiofilm potential against methicillin resistant Staphylococcus aureus and Klebsiella pneumoniae. Int. J Nanomedicine. 2019;14:3983-93.

13. El-Naggar NE, Hussein MH, El-Sawah AA. Phycobiliprotein-mediated synthesis of biogenic silver nanoparticles, characterization, in vitro and in vivo assessment of anticancer activities. Sci Rep. 2018;8(1):1-20.

14. Braakhuis HM, Gosens I, Krystek P, Boere JA, Cassee FR, Fokkens PH, et al. Particle size dependent deposition and pulmonary inflammation after short-term inhalation of silver nanoparticles. Part Fibre Toxicol. 2014;11(1):1-16.

15. Brand-Williams W, Cuvelier ME, Berset CL. Use of a free radical method to evaluate antioxidant activity. LWT-Food Sci Technol. 1995;28(1):25-30.

16. Gnanakani PE, Santhanam P, Premkumar K, Kumar KE, Dhanaraju MD. Nannochloropsis Extract-Mediated Synthesis of Biogenic Silver Nanoparticles,
Characterization and in vitro Assessment of Antimicrobial, Antioxidant and Cytotoxic Activities. Asian Pac J Cancer Prev. 2019;20(8):2353-64.

17. Thakur $P$, Kumar $V$. Kinetics and thermodynamic studies for removal of methylene blue dye by biosynthesize copper oxide nanoparticles and its antibacterial activity. J Environ Health Sci Eng. 2019;17(1):367-76.

18. Maziero JS, Thipe VC, Rogero SO, Cavalcante AK, Damasceno KC, Ormenio MB, et al. Species-Specific in vitro and in vivo Evaluation of Toxicity of Silver Nanoparticles Stabilized with Gum Arabic Protein. Int. J Nanomedicine. 2020;15:7359-76.

19. Alqahtani MA, AlOthman MR, Mohammed AE. Bio fabrication of silver nanoparticles with antibacterial and cytotoxic abilities using lichens. Sci Rep. 2020;10(1):1-17.

20. Abdollahnia M, Makhdoumi A, Mashreghi M, Eshghi $H$. Exploring the potentials of halophilic prokaryotes from a solar saltern for synthesizing nanoparticles: The case of silver and selenium. Plos One. 2020;15(3):1-18.

21. Rosman NS, Harun NA, Idris I, Ismail WI. Eco-friendly silver nanoparticles (AgNPs) fabricated by green synthesis using the crude extract of marine polychaete, Marphysa moribidii: Biosynthesis, characterisation, and antibacterial applications. Heliyon. 2020;6(11):e05462.

22. Marjoni MR, Zulfisa A. Antioxidant activity of methanol extract/fractions of senggani leaves (Melastoma candidum D. Don). Pharm Anal Acta. 2017;8(8):1-6

23. Gomathi S, Firdous J, Bharathi V. Phytochemical screening of silver nanoparticles extract of Eugenia jambolana using Fourier infrared spectroscopy. Int J Res Pharm Sci. 2017;8(3):383-7.

24. Brause R, Moeltgen H, Kleinermanns K. Characterization of laser-ablated and chemically reduced silver colloids in aqueous solution by UVNIS spectroscopy and STM/SEM microscopy. Appl Phys B. 2002;75(6):711-6.

25. Nikita D, Sankar B, Ashamoni N, Rajib. B. Correlation of Surface Plasmon Resonance Wavelength (SPR) with Size and Concentration of Noble Metal Nanoparticles. Ann Rev Resear. 2019;5:50-5

26. Reddy NJ, Vali DN, Rani M, Rani SS. Evaluation of antioxidant, antibacterial and cytotoxic effects of green synthesized silver nanoparticles by Piper longum fruit. Mate Sci and Eng C Mater Biol Appl. 2014;34:115-22.

27. Moldovan B, David L, Achim M, Clichici S, Filip GA. A green approach to phytomediated synthesis of silver nanoparticles using Sambucus nigra L. fruits extract and their antioxidant activity. J Mol Liq. 2016;221:271-8.

28. Logaranjan K, Raiza AJ, Gopinath SC, Chen Y, Pandian K. Shape-and sizecontrolled synthesis of silver nanoparticles using Aloe vera plant extract and their antimicrobial activity. Nanoscale Res Let. 2016;11(1):1-9.

29. Parveen M, Ahmad F, Malla AM, Azaz S. Microwave-assisted green synthesis of silver nanoparticles from Fraxinus excelsior leaf extract and its antioxidant assay. Appl Nanosci. 2016;6(2):267-76.

30. Jun M, Fu HY, Hong J, Wan X, Yang CS, Ho CT. Comparison of antioxidant activities of isoflavones from kudzu root (Pueraria lobata Ohwi). J Food Sci. 2003;68(6):2117-22

31. Abdel-Aziz MS, Shaheen MS, El-Nekeety AA, Abdel-Wahhab MA. Antioxidant and antibacterial activity of silver nanoparticles biosynthesized using Chenopodium murale leaf extract. J Saudi Chem Soc. 2014;18(4):356-63.

32. Velammal SP, Devi TA, Amaladhas TP. Antioxidant, antimicrobial and cytotoxic activities of silver and gold nanoparticles synthesized using Plumbago zeylanica bark. J Nanostruct Chemistry. 2016;6(3):247-60.

Cite this article: Swapna G, Rao BK. Green Synthesis and Characterization of Silver Nanoparticles from Stem Bark Extract of Cordia dichotoma G. Forst and Evaluation of their Antioxidant and Antibacterial activities. Pharmacog Res. 2021;13(3):158-64. 
GRAPHICAL ABSTRACT

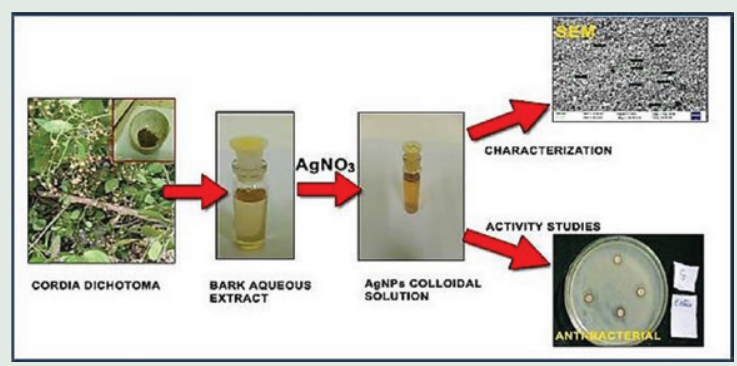

\section{SUMMARY}

Silver at the nanoscale level provides excellent, efficient altered physical and chemical properties and which can be further enhanced when the fabrication on synthesis method is through plant extract-based bio reduction. In the present study, AgNPs were synthesised by using stem bark aqueous extract of the Cordia dichotoma. The synthesized AgNPS were characterized by various spectroscopic and microscopic techniques such as U.V-Visible, FT-IR, SEM, EDAX, Particle analyzer, and Zeta potential. From the results, it can be inferred and concluded that the synthesized AgNPs have all the structural and physical characteristic properties to be considered as nanoparticles with potential therapeutic applications viz., antioxidant and antibacterial activity against both Gram-positive and Gram-negative pathogenic bacteria. As natural or synthetic antioxidants have limitations of degradation during delivery and poor bioavailability, the AgNPs synthesized using Cordia dichotoma can be best explored to use as natural antioxidants. However, bio-efficacy studies are needed to be performed in animals. 